\title{
Discussions on the Cultivation of the Ethical Consciousness of Nursing Students in the Medical Nursing Teaching
}

\author{
Du Weihua
}

Hexi University, Zhangye city, Gansu province, 734000

Keywords: nursing ethics; medical care; osmosis

\begin{abstract}
Today, with the rapid development of nursing science, the relationship between nurses and patients has attracted much attention. In the development of the hospital, it is necessary to deal with the relationship between nurses and patients properly. In order to improve the reform of medicine, the nursing profession should also train qualified personnel with high quality, and the technical level of nursing staff needs to be further promoted. The education of nursing ethics is a very important content. This paper analyzes the ethics education of nursing.
\end{abstract}

As an excellent nurse, it is important to master the ethical knowledge of nursing, have excellent nursing skills, but also have noble moral cultivation and perfect ethical norms. So, in the medical nursing teaching, nursing professional teaching, teachers should improve the moral and ethical education, which will have an important effect on the students, and on their standard behavior.

\section{The significance of the cultivation of nursing ethics and morality}

Now, there are great differences in the cultural level and moral cultivation of the nurses in each hospital, which leads to the uneven ethical and moral quality of the nursing staff. There is still a certain gap between the ethical and ethical behaviors of hospitals and the national expectations. Nurses can not fully respect the privacy of patients, and can not fully support patients emotionally. Therefore, the nursing work of the hospital should be perfected continuously, and the ethics and morality of the nursing staff should be cultivated [1].

Improving the cultivation of nursing ethics is the need of the nursing profession. The fundamental purpose of nursing is to realize the care of patients, as a qualified nursing staff in medical nursing teaching, should combine moral education, proper education of the nursing staff, can improve their comprehensive quality to a certain extent.

Nowadays, the competition among hospitals is also fierce. To improve their service ability, hospitals must enhance the quality of nursing care, educate professional nurses and improve nurse patient relationship. Nurses should cooperate with and help patients, so that they can successfully complete the treatment. In the whole process, if the neglect of personnel has no better ethical quality, the quality of hospital care is bound to be affected [2].

The nursing staff should often communicate with patients, so to improve nursing ethics education, to improve the comprehensive quality of nursing staff, so that their inner feelings can be inspired, the formation of good moral character, adhere to the moral standards in nursing care in nursing work can make patients more satisfied.

\section{The problems existing in the teaching of medical nursing}

Now, medical nursing students are generally 90 years old. Their thinking is very active, and their ability to accept fresh ideas is very strong. They are not willing to stick to rules in learning, have the ability of acquiring knowledge through multiple channels, and dare to innovate and practice. This generation is full of confidence, but most of them are self centered, and they cannot fully consider the others, and their sense of responsibility is poor. Therefore, in the links of internal medicine nursing teaching, teachers should improve nurses' sense of service and improve ethical services, so that they can have a sense of social responsibility and form good social conscience. 
The interpersonal communication ability of the students majoring in medical nursing needs to be further improved, their interpersonal communication ability is poor and the scope of communication is relatively small. A lot of nursing students are not willing to communicate with patients actively, they can not quickly integrate into the group in their work. And a lot of nursing students' cooperation consciousness is poor, they do not pay attention to the feelings of others, in the nursing work, always hold the responsibility of relevant none of my business, need to improve. In practical clinical work, if other nurses need help, many nursing students are in a mood of conflict. They cannot actively cooperate and help other nursing staff. In clinical work, if other nursing staff fail, or because of other reasons, they cannot be on duty. Many nursing students are very indifferent. They can't care for their colleagues or take the initiative to help them [3].

In the actual clinical nursing work, the psychological quality of many nursing staff needs to be further promoted. They are exposed to some sources of pollution in their work. Therefore, nursing students will have a psychological conflict with their patients' life care. Some nursing students even think that nursing work is waiting for patients, which is a very low work. In peacetime practice, if they can not communicate with patients normally, they will often abandon themselves, unable to take the right way to solve problems in their work, and even some nursing students are very depressed in their work. Nursing students should learn to adjust their emotions in the working process, solve problems in specific situations, and improve their psychological quality, so that they can better adapt to the nursing industry.

Students in the learning process, accept the cramming way of learning, students not to take the initiative to learn the knowledge. In the actual teaching, teachers can not find every student in the study. Therefore, the nursing students should study actively and find out the problems in their study. If they still have doubts, they should ask teachers in a timely manner.

\section{The ways of cultivating the ethics and morality of nursing students in the teaching of medical nursing}

As a qualified nursing staff, we should not only have solid medical ethics knowledge, but also improve the skills of nursing operation. In the process of providing all services to the patient, there should be high moral and ethical behavior. In the specific nursing work, nursing ethics mainly refers to that nurses should adjust the relationship between nurses and patients in appropriate ways, and nursing ethics should be combined with moral standards in nursing work. In the links of internal medicine nursing teaching, we should improve nursing ethics education. Nurses should strictly provide ethical care for patients in their work and work hard to solve ethical problems in nursing work, so as to improve the construction of harmonious environment. In the improvement of nursing ethics education, the research of nursing research should be perfected so as to make the nursing profession develop in a better direction. Nurses should improve ethical education before going to work, combine theory and practice organically, improve the quality of nursing, and train high-quality talents in medical nursing education. In specific teaching activities, teachers should improve the cultivation of moral consciousness and ensure that nurses can implement ethical and moral concepts in specific work. Nowadays, the growth environment of nursing students is very good, their personality is good, and the ability to accept new things is very strong, but they lack the cognitive ability in nursing work. A lot of nursing students think that nursing work is low work, so their enthusiasm for learning is not high. In the course of receiving professional learning, they can not pay attention to the mechanism of the related diseases. In order to solve the above problems, teachers should improve the cognitive structure of nursing students in the teaching of medical nursing. Nursing students should constantly improve the position of nursing work in the medical system. In the nursing links of elderly diabetic patients, we should understand the psychological characteristics of the patients based on the understanding of the disease, so that we can meticulously care, so that we can get patients' trust. Internal medicine professional nursing teachers should not only transmit professional knowledge to students, but also adopt practical case teaching methods, penetrate theoretical knowledge into actual cases, and improve the education of nursing ethics [4].

In the clinical manifestation of the nursing students, it can be seen that the moral consciousness 
of the nursing students should be further improved. In the course of professional learning, the teachers only impart their knowledge, but they do not carry out ideological and moral education to them. Under such circumstances, medical nursing education should ensure that students establish good ethics and constantly control students' Ideological and moral quality through education. Only in this way, the nursing students can show good professional accomplishment in the later nursing work, and the patient's privacy can be fully respected in the clinical nursing. In the teaching process, we should improve the ethics of nursing students, and adopt a variety of teaching methods to make nursing more attractive and enhance the interest of nursing students. In teaching, teachers should not only teach knowledge in books, but also extend extracurricular activities for teaching materials and broaden their knowledge. In view of the actual teaching situation, the social hot issues are combined with the knowledge on books so that the moral and moral of the students can be promoted. In order to make the nursing students' knowledge of the continuous improvement of the clinical medicine and the social hot spots, we should improve the students' sense of social ethics, will let the students focus analysis, in order to make students fully aware of the importance of follow ethics in nursing, so that students in the work of the implementation of the operation in accordance with the code of ethics. In the course of teaching activities, teachers should divide the content of teaching and integrate into social hot spots, which can lead to students' thinking. Teachers should also introduce actual cases into teaching, adopt various teaching methods, diverge the social hot spots according to different teaching contents, and lead students to think more. In the teaching, the case should be introduced into the teaching, and the multimedia teaching method should be adopted to enable the students to learn more knowledge with the help of the Internet [5] .

After the students perceive the outside world, they will have a certain psychological reaction, and then they will show their emotions. The future career of the nursing students is the nurse, who will be in contact with patients with different diseases in their work. Patients are often exposed to negative emotions because of their suffering. The diet of many patients will be very difficult, it needs people's help, the incontinence of the patient, some patients need the care of the wound. If nursing students can't establish good professional emotions in their learning, they can't protect their privacy and respect patients. The sense of responsibility is integrated into the nursing ethics and emotion. They will produce emotional changes in their work. In the teaching of medical nursing, teachers should continuously infiltrate into this part and set up a platform for nursing ethics teaching. The course of medical nursing not only has a lot of theoretical knowledge, but also has strong practicality. In the ethics teaching, teachers can provide certain situations for students, so that students can feel themselves on the scene, so that students can have a sense of clinical substitution.

In the links of internal medicine nursing teaching, we should fully integrate the teaching of nursing ethics, and the two should be closely related, so as to effectively enhance the professional quality of nursing students. Medical nursing occupies a very important position in the course of nursing specialty, which is of great significance in practice. In the actual teaching link, the teacher should choose the appropriate teaching case according to the content of the course, so that the student can carry on the practical operation. Teachers and students can play the roles of nursing staff and patients respectively, so that students can think of problems from the perspective of patients and perceive nursing work from multiple perspectives. In the teaching of medical care, ethical and moral education is run through all the time, so that students can actively invest in learning and stimulate their desire for knowledge. Students in practice, their comprehensive ability can be steadily improved, and can provide more quality services for the patients [6].

In the course of teaching, teachers should carry out various activities so that the comprehensive ability of the nursing students will be steadily improved. First, teachers should cultivate students' ability to care for others, create a good humanistic environment for them, and integrate them into more roles. Through various roles, students can fully understand the psychology of all social roles. On the basis of classroom teaching, we should also improve the humanistic care of nursing students, cultivate their ethics and morals, create a strong humanistic atmosphere for them, and enable them to understand solidarity and respect for others in various activities. 3.6building a communication platform and edifying the sentiments 
In the links of internal medicine nursing teaching, teachers should set up communication platform for nursing students, so that their body and mind can be infected, enhance their ethics and moral cultivation, and create perfect personality of nursing students. Nursing students are relatively young. They will fully use the Internet to get information. Teachers can build a network platform, answer students' questions in time on the network platform, and grasp students' ideological trend in time. Teachers can also make timely evaluations and feedback on the platform. Platform building not only improves the learning efficiency of students, but also helps to communicate between teachers and students. The nursing profession can also carry out regular lectures, so as to improve communication and improve the interpersonal communication ability of the nursing students.

Teachers should give full play to the role of demonstration in teaching, so as to imperceptibly influence students, enhance students' ethics and morality, and form perfect professional ethics. Teachers in the teaching, can show the students ethical literacy, the teacher's professional ethics have a profound impact on students. A teacher should not only enhance their professional knowledge and teaching ability, should also enhance their moral quality and ethics, make their own words and deeds and give full play to the effect. In the teaching, the teacher should play a leading role, especially in the practice teaching, the teacher should take an example to infect the students with a strict attitude. Teachers should show their own teaching characteristics in order to mobilize students' learning enthusiasm and inspire their sympathy in practical work.

\section{Conclusions}

In the link of medical nursing teaching, teachers should fully combine the characteristics of the students, choose the most suitable teaching methods, and improve the students' ethical consciousness. In teaching, we should integrate into the traditional culture of central ethnic group, combine problem teaching method and situational teaching method, so as to improve students' ethical awareness and enable them to better finish nursing work.

\section{References}

[1] Yu Xi. An analysis of the training of the ethical consciousness of nursing students in the teaching of medical care in [J]. course, 2016, (05): 36.

[2] Cai Z, Xia B J, Liu Z Q. Discussion on the cultivation of three kinds of consciousness in pharmaceutics teaching [J]. China Medical Herald, 2009.

[3] Liao R Y. Discussion on the Cultivation of the Social Responsibilities Consciousness of the College Students [J]. Journal of Huanggang Polytechnic, 2008.

[4] Chen Y. Discussion on Cultivation of Students' Humanized Service Consciousness in Community Nursing Teaching [J]. Journal of Yueyang Vocational Technical College, 2009.

[5] Luan H S. Stress the cultivation of student's legal consciousness in basic nursing teaching [J]. Journal of Anhui Health Vocational \& Technical College, 2005.

[6] Wang Y L, Jian H E, Meng M. Exploration on Cultivation Model Reform of Hospice Care Capability for Undergraduate Nursing Students [J]. Chinese Medical Ethics, 2011. 